\title{
Feminist Standpoint and Question of Women Participation in Decision-Making, in Nepal
}

\author{
Binda Pandey
}

\begin{abstract}
Feminist standpoint theory emerged in the 1970s. As a feminist critical theory it focuses on the relationship between the production of knowledge and practices of power. It can be considered as a blended form of Marxist feminist, critical theory and a range of social scientific disciplines. Feminist standpoint helps to understand and explain the world through marginalized, subordinated and oppressed women's point of view in the society considering them as knowledgeable. It is the process of mainstreaming their knowledge, skill and experiences. Feminist standpoint focuses on power relations, which is broadly cultivated on cultural values and assigned gender role. In this context, feminist standpoint could be a theoretical basis to mainstream women's knowledge, skill and experiences, instead of conventional way of thinking and doing things with taking into account the knowledge and experiences of dominant groups.

Keywords: decision making, feminist movements, Nepal, socialist feminist
\end{abstract}

\section{Introduction}

In the changing context of human society, balanced women's participation in decision making is the issue of the redistribution of power. This essentially gear up their quality intervention and to move forward achieving gender justice. It will make possible to maximise and mobilise full human potential for the cause of nation's prosperity. For the cause, feminist standpoint should be taken into 
consideration in research process digging out and mainstream the knowledge, skill and experiences of the women from margianlised, oppressed and subordinated group. And, their participation in decision making process is essential to reveal all these in action.

World feminist movement arrives in the conclusion that women participation in decision-making process with correct standpoint is must. Changing the world seeing balanced, just and sensitive through gender point of view is must. Main objective of the feminist standpoint is to mainstream marginalized, oppressed and subordinated knowledge, skill and their life experiences of women to achieve egalitarian society, which demands to hammer out the socio-cultural norms and practices which are deep-rooted in patriarchal values. In these context, women participation in rank and file as well as decision-making mechanism is fundamental; in order to strengthen the process of social transformation having dignity and justice. In this paper I would ask a question whether different experiences and knowledge of women has been acknowledged and recognized in the process of public decision-making in Nepal.

\section{Overview of the Standpoint Theory}

Merriam Webster dictionary defines "standpoint" as a "position" from which objects or principles are viewed. This is associated with comparing and judging the matters. Similarly, the encyclopedia of communication theory has pointed out that standpoint arises when an individual recognizes and challenges cultural values and power relation that contributes subordination or oppression in a particular society (Little john \& Foss, n.d.)

Feminist standpoint focuses on marginalized and relatively invisible women. It further defines the feminist standpoint with reference to some of the feminist theorists such as Dorothy Smith, Nancy Hartsock, Donna Haraway, Sandra Harding, Alison Wylie, and Patricia Hill Collins. This is related with how knowledge is neither valueinnocent nor value-free from the cultural contradictions. In social science, scholars believe that the process of producing knowledge and experiences is always value-laden (Preece (n.d.) quoted Code (1991). Taking these views and definition into consideration, people in the society can be categorized into two groups: dominant as 


\section{4| Binda Pandey}

centered and dominated as marginalized. Conventionally, most of the decisions are influenced by the people of the dominant groups. Feminist think that the people from the marginalized group should also be considered as knowledgeable and experienced equally. In my opinion, such knowledge and experiences certainly helps to formulate good policy to bring justifiable change.

Hekman (1997) mentioned that Nancy Hartsock is the person to bring this theory first time in the discussion. She blended Marxist feminist, critical theory and a range of social scientific disciplines. As she claimed feminist standpoint is the way to understand and explain the world, through women's point of view as marginalized, subordinated and oppressed group in the society. Harding (2004) says that feminist standpoint 'as a feminist critical theory about relations between the production of knowledge and practices of power'. Crawford (n.d.) broadens the perspective saying that the standpoint theories are not a uniquely feminist phenomenon. They can be found in a number of different branches of sociology, along the different branches of the feminism.

As Wincler (2004) said that the feminist movement in sociology was shaped by liberal, Marxist, socialist and radical feminism. Liberal feminist sociologists stress on investigating barriers to equality and socialization into gender roles and argue that most of the differences between men and women are superficial at best. Radical feminist sociologists see that matter differently and focused their attention on patriarchy's appropriation and exploitation of the female body.

Marxist and socialist defined the primary source of oppression as economic system that created systems of exploitation. Sociologists of these category investigated economics, labor market, household and the state.

From these perspective standpoint theory can be synthesized as the process to mainstream the knowledge, skill and experiences of marginalized people, where the inequalities is located in gender, race, class, and sexual orientation with social hierarchy. It is crucial to define relationship between power and knowledge in terms of the standpoint theory.

According to Harding (2004), different feminists have advocated 
the feminist standpoint differently. It is important to note that they have different views on their aim, scope and purpose. As Benton \& Craib (2001) say Nancy Hartsock sought to synthesize a feminist standpoint with the humanist materialism of early Marx. Hartsock draws attention that women indeed hold position differently from men in society, because of women's dual role as wage and domestic worker. In the context of knowledge, Hekman (1997) says, "the feminist standpoint theory represents the beginning of a paradigm shift in the concept of knowledge, a shift that is transforming not only feminist theory but also epistemology itself'. Therefore, having review of all these opinion, logic and facts, we can say that feminist standpoint theory has been developed to mainstream the knowledge kept in peripheral, marginalized, dominated and subordinated position and surfacing the reality by digging out the life experiences of women.

The feminist standpoint theory and feminist research has some common ground as Speedy (1991) has identified three main principles in regards to feminist research: "(a) recognition of women as oppressed community and examine the reason to take action for change, (b) valuing of women's experiences and (c) do consciousness-raising as alternative views of the world from woman's perspective".

\section{Foundation of the Standpoint theory}

Feminist standpoint is broadly focused on women's knowledge cultivated based on cultural values and power relation by assigned gender role. He further explains that feminist standpoint theorists in general make three principles as (a) knowledge is socially situated, (b) marginalized groups make it more aware to ask questions and (c) the research focused on power relations (Bowell, 2011).

According to Crowford (n.d.), feminist standpoint theory has been developed as the extension of Marx's class standpoint theory. The feminist scholars from different disciplines have advocated feminist standpoint as taking women's lived experiences, particularly experiences of caring work. Central to all these arguments, feminist standpoint theories are feminist analyses and critiques of relations between material experiences and the effects of power relations on 


\section{6| Binda Pandey}

the production of knowledge. Feminist standpoint expresses female experiences at a particular time and place, located within a particular set of social relations. She further stated that the feminist standpoint allows us to go beneath the surface of appearances to reveal the real but concealed social relation (Hekman, 1997).

The heart of Hartsock's argument and claim is that unless we provide a systematic understanding of the world, we will be unable to change it. It is linked with political and social power and knowledge. And, it describes and analyzes the cause and effects relation of power structures on knowledge.

Feminist standpoint theorists believe on diversity among women, their experiences and knowledge that varies due to unique social, political and economic background. They stress gender mainstreaming in all sectors of social structure and recognition of women's leadership and knowledge. This can be driving vehicle toward social transformation.

Brooks (n.d.) mentions that feminist standpoint epistemology is a unique philosophy of knowledge building that challenges us to see and understand the world through the eyes and experiences of oppressed women; apply their vision and knowledge into social activism and social change. Feminist research model works on the theoretical proposition that women's personal and social experience are in a better position than men to face and understand the world of women.

If we reflect the Nepali society from feminist standpoint, one can find that it is still dominated by patriarchal norms and values in practice, although many laws and policies have been changed recently based on view points of gender equality. It might be possible to implement properly within some time. For the cause, the leaders in politics as well as in social movement should take the feminist epistemology into consideration and ensure the ontological shift to include women's lived experiences in the process of social change and development. 
Feminist movement in the world was started in middle the of $19^{\text {th }}$ century from industrialized countries and continued until the end of World War first which is termed as first wave. The movement concerned mainly to fulfill the basic need of human being giving priority over cheaper food, cloth, shelter and education, and employment. In those days, feminist were not giving much emphasis on the issues of participation in decision-making.

Since feminist movement entered into the second wave feminism onward 1960, the feminist standpoint emerged and hence demanded different power relation. It was the time when feminists started to argue about the care ontology of knowledge as well as use of feminist epistemology to see the different apparatus of producing knowledge such as culture, religion, class, etc., and women's participation in decision-making process (Krolokke, 2000). Women started to analyze their knowledge collectively, which was acquired through their own life experiences. As result, feminist movement arrived in a conclusion that women participation in decision-making is must in order to change the world for balanced, just and sensitive through women's point of view.

The issue of the women's participation of critical mass was institutionalized after fourth world women conference in Beijing, 1995 (in Beijing Platform of Action). Before that in different countries, they were using their standpoint theory in regard to participate women in decision-making process. It has made some differences. Later, cause by the national and international efforts, women participation in the world has been tripled in parliamentarians during last two decades. It has reached 22 percent (IPU, 2015), which is remarkably increased. But, the progress is still far behind than the critical mass as 33 percent, set by Beijing conference.

The third wave feminism started from decade of 1990s realized diversity among the women by their experiences and knowledge. Kralik and Loon (n.d.) have concluded their research through feminist standpoint found that most women face some forms of oppression and exploitation. They experience their oppression, struggles and strengths in various ways because of their diverse realities and identities as women. In this connection, the contemporary 


\section{8| Binda Pandey}

feminist movement has realized that to respect and include diverse experiences of women, there should be flexibility in the feminist standpoint as well. This process of addressing the marginalized community can be known as epistemological paradigm shift. It is also called ontological process of inclusion, which is one of the top most issues established by the people's movement in 2006 in Nepali society.

\section{Philosophy behind the Standpoint View}

There are different philosophies about the human society since Vedic time. During Vedic world the concept of Ardhanareswor, was considered as the symbol of perfection of human being, which is composed of half male and half female character. It is interpreted as representation of the synthesized energies of masculine and feminine of the universe. It illustrates the ideology of inseparable male and female power (Reddy, 2010). There is another interpretation in RhigVeda that male as sun and female as rays, which is related with interdependence of their relations as understood as Ardhanareshwor. Reddy has mentioned that in RhigVeda Purush (male) cannot manifest without Prakriti (female) and Prakriti cannot be visible without Purush. Male and female characters in the human society complement and supplement each other in the process of making human views and life complete. It reciprocates mutual respect, neediness and harmony to move toward perfection of relation based on theory of equity.

For this theory, gender based discrimination is the product of imbalance nature and deficiency of cooping character between two sexes. It stands on the philosophy of co-existence of male and female in human society. It gives a kind of philosophical standpoint to see gender relation, which was seen during Vedic period.

Today's material based world has different philosophical view to see human being and relations between male and female as having different nature, need, demands and characters. It views male and female differently not only based on biology. They are differences in psychology and mentality, which cause difference in human needs and necessity as well. That is why things have to be dealt differently to make them substantively equal. 
Judging the differences in knowledge and experiences between women and men are whether imply in reality or not. For instance, Lieberman's argument can be taken into account. A primary discrepancy is noted in the different communication styles found in each gender. While females use communication as a means of connection, males have a tendency to converse in hopes of being assertive and gaining power.

Lieberman (in Difference in Male and Female Communication Styles) as a gender analyst argue that there are some differences even in communication style between men and women. For instance, women normally nod her head to make sure that she is listening, but men understood it differently as she is agreeing on the matter. Finally, when she differs on matter, then man surprise. Similarly, if there is some disagreement between women, it affects almost everything. But, in the case of men they leave the matter of disagreement and turn into next subject, where they can work together. These are some different gendered style of the communication and work, which is caused by their sex differences.

Merchant (2012) says regarding different in communication style use by women and men. She views in Basow \& Rubenfield (2003) as women in overall are more expressive, tentative, and polite in conversation, while men are more assertive and power-hungry. She further mentions the works by Gray (1992) and Deborah Tannen (1990) which shows that while men view conversations as a way to establish and maintain status and dominance in relationships and women see the purpose of conversation to create and foster an intimate bond with the other party by talking about topical problems and issues they are communally facing. Referring Lakoff (1975), Merchant has mentioned in her paper that women use less powerful speech: they tend to swear less, speak more politely and use more tag questions and intensifiers. Women tend to interrupt less than men. But, Solberg (2013) differ the above idea and said differences can be influenced by social culture and human behavior, which cannot be universal and static. It can keep changing. She further said men and women don't have different styles of working leadership. In her opinion, differences in the leadership style are outcome of the working environment with gender balance and gender equality in 


\section{0| Binda Pandey}

organizations. It is matter of external environment, enabling with gender perspective.

Supporting the saying as architect of the brain is gendered, cause the differences in nature and way of thinking and performance, Gur (n.d.) says that the hardwired difference between male and female brains. And, it could explain why men are 'better at map reading and women in remembering a conversation? He further said "detailed connectome maps of the brain will not only help us to have better understanding the differences between how men and women think, but it will also give us more insight into the roots of neurological disorders, which are often sex related". It reveals significance difference between men and women.

There is no single reality in the world. Though the matter of the gender relation and issues are same, but the way of viewing the things make it different. Finally, different people see the fact in their own-way and produce the logic differently, caused by different standpoint and ontology to experience the object. Obviously the feminist standpoint view as well makes difference in convention way of viewing.

Feminist standpoint is the way to see the matter with feminist epistemology, which can have differences in foundation based on different region, profession, culture, society etc. And, the perspectives on existence and role of different sexes are not only different, but sometimes controversial as well. Because, some see masculine and feminine character complement each other. Other see totally different as connectome maps of the brain architect, which make different in thinking, skill and performance. It reveals that there is no single philosophical viewpoint to see a single fact. It means there is no single reality in the world.

In general, Nepali society is fast and simply accommodate new ideas. But in practice, it is still valuing stereotype, keeping close legacy of centuries long feudalism and patriarchy. Being a fast changing society, it has realized the idea of gender equality. But, women's knowledge and experiences are yet to be mainstreamed. Use of feminist standpoint to dig out the social reality of women's lives, for the sake of social transformation is yet to be realized and 
adopted. It is important to be clear about the philosophical point of view to take into consideration in the course of change. The modern philosophy of gender equality is dominant as principle. And, the ancient philosophy based on the theory of co-existence and cooperation from Vedic time is equally influential in practice. This dichotomy in principle and practice may need to amalgam to see new dimension in the debate of feminist standpoint. In fact the third wave of feminism is trying to bring both together and promote the theory of 'pedagogy of oppressed'.

\section{Feminist Standpoint in Decision-making}

Feminist standpoint is different from the conventional way of thinking and doing. It does not only take into consideration of mainstream knowledge and experiences of dominant groups. As Walker (2003) says that feminist standpoint is the way of decisionmaking having some differences in the ethical and moral system, which brings the knowledge, skill and experiences of subordinated and marginalized group into center-point.

Working with the feminist theory, DeVore \& Martin (2008) say there are four overarching themes such as belief system, decision-making, challenges of ethical leadership and professional development process. All these four themes are interrelated in terms of making knowledge and experience differently. Belief system is also closely linked with the moral value and social ethics. Belief sysem and ethic are influencing factors to experience the circumstances in the process of making decision. It recognises the multiple reality of the world. People's perspective makes difference in knowledge production process. Identifying the challenges and use professional expertize to tackle that depends on how to internalise the matters as well. Decision-making process standing on Vedic Philosophy emphasize on trust relationships, consistent, description of the complex and difficult situation, which focus on de-escalating future conflict. Their believe and ways of thinking determines how human beings perceive and understand the surrounding world (Nisbett, Peng, Choi, \& Norenzayan, 2001). These themes and perspective in the process of seeing things make different based on gender. It means feminist standpoint may prevail differently.

Though, there are long list to see differences between men and women 


\section{2| Binda Pandey}

in the decision-making position, but our life experiences simply says that shift in the political position make shift in the way of thinking as well. Shifting the pattern of participation in economic production and its relation, shift the perception to see gender relation.

Experiences of the women's movement have shown different dynamics in the process. While women are in the inferior and peripheral position, they are more vocal and focal on women agenda. But, after moving to the core area of the decision-making, specially in the political position, there are two possible way of changing perspective and role. First, if she is philosophically and ideologically strong enough on the issues, her effort would be maximized shifting the decision-making paradigm and brings 'in the feminist standpoint' in the process. If her political perception is not strong enough to put forth the issues logically to motivate other, she herself will be taking shift slowly toward conventional side and be supportive of traditional stand in the society, which is yet, much influenced by patriarchy.

Our own past experiences of the women's movement have shown that to go through the first option is very tough and very few have been sustained after assuming power position. And, there are more chances for the second one to be happened. It is still need to study in depth whether cultural value of grown up of every human is more influential than ideology and movement in this matter? In this regard, the issue of gender equality in citizenship provision can be taken as example and analyze the perspectives of senior women leader, how they took turn from the stand of equality in process of promulgating new constitution, 2015 and try to justify discriminatory provision with conventional logic. It is the matter of philosophical clarity.

There are some approaches to observe feminist ethic such as carefocused and status-focused. As Gilligan (1982), feminist carefocused ethicists notice female subordination and the tendencies of patriarchal societies do not properly esteem women's ways of thinking, writing, working, and loving. Status-focused feminist approaches to ethics tend to ask questions about power and view systematic subordination of women to men in many different ways. And, destruction of those systems, structures, institutions, and practices, which differentiate power between sexes, is the necessary 
prerequisite to create gender equality with standpoint.

Mitchell \& Mishra (2000) argues that women's role in production, reproduction, sexuality and the socialization of children determine women's status in the society. And they say gender role in all these structures must be changed to be equal as men, substantively. They further add in psychoanalysis and feminism, women's interior world, their psyches must also be transformed. Unless women are convinced of their own value, change in their exterior world cannot totally liberate them (Mitchell et.al. 2000). These ideas are considered as the modern view on existence of gender imbalance in society and proposed opinion of remedy.

But, women and men are little different socially and as role, responsibility and performance, based on biological differences. Taking nature given different roles into consideration in regards to achieve the equal human status rather to be equal to men, differences in policy and behavior should be practiced. The philosophical thinking plays great role in these matters. The way of taking men as symbol of human standard need paradigm shift in the way of thinking for proper apply of feminist epistemology.

Feminist process validates and brings into focus the emotional underpinnings of our intellectual and political relationships. The goal of feminist process is to open up more space for participation and to create an environment, where the least confident among us feels it is safe to speak up (in what is feminist process?). Similarly, the values and strategies such as mutual respect, consensus decision making, shared power and non-hierarchical structures were seen as integral elements to these alternative spaces for women (Miles, 2002). Broader and open discussion may help enabling the environment to speak up people comfortably. This may help to mainstream the marginalize idea, which is the goal of the feminist standpoint.

The goal of the feminist standpoint in decision-making process is to achieve respectful dialogue in the context of careful listening of marginalized voice where every person feels affirmed in the value of their ideas and their contributions to the group and be very careful not to speak in a way that demeans the other person or their ideas. Respectful dialogue requires active listening technique, which helps 


\section{4| Binda Pandey}

to be less defensive in responding to criticism or disagreement (in what is feminist process?).

Here the question comes whether we follow feminist standpoint in decision-making process or not. My experience as a former parliamentarian for four years and as a central committee member of a communist party of Nepal (UML) since 2009, I did realize that the acceptance of neither Vedic nor modern type of feminist standpoint in the decision-making process. For instance, there were series of meeting taking place in the constitution making process. Women and many marginalized group were raising their voice based on knowledge and experiences of periphery. But, they were neither listened seriously nor included in the process. All the parties' leader (male), considering themselves senior, took the matter in conventional way and decided based on their pre-occupied mind. Decision-making was almost similar in all political parties, who think themselves as better choreographer of the people. It reflects that only ideological principle of the parties and physical presences of women do not make intended gender change in politics and process. Deep-rooted feminist sensitivity in mind and heart among decision maker is necessary to make paradigm shift in the ontology as well as epistemology to end gender discrimination as output.

\section{Feminist Standpoint in Nepali Context}

It is an evolution of the ideas, issues and ways of action. Biological differences in male and female make certain differences in needs and perspective. It produces different experiences, social construction and approaches that make differences in feminist standpoint.

Feminism is not a single phenomenon to move forward to achieve tangible equality in society, having feeling of respect and inclusion of different knowledge and experiences for the benefit of social transformation toward social justice. Liberal feminist campaign was started in 19th century, aiming to have equality through changing in policy and law. Rest, women and men could compete in personal capacity to diminish the gender gap. It could happen somehow in the process. Since, the patriarchy is deep rooted in social culture, equality in paper did not work to make tangible change in women's life as collective. 
Then the idea took the turn to radical feminism believing that main rival of women is patriarchy, which guarantees male supremacy and the subordination of women at work and in the home. They claim, men are the enemy of women and women as sexual class, and consider patriarchy as universal cause of exploitation of women by men. Taking this perspective in social construction, radical feminist standpoint succeeded to establish the issues, as unless addressing the women's agendas as collective, it is not possible to win over the subordinated condition fight as person. But, it could not direct the proper way out. Because, having mono-sex society is not possible in reality and sex based social rivalry can create social unrest rather bringing equality.

Marxist feminism believes as social class is a key factor and capitalist class relationship is the root cause of female oppression, exploitation and discrimination. The concept of social class is considered to be more important than the concept of patriarchy since the latter is seen as a form of ideology that stems from class exploitation. This ideology motivate

Booth, Creamer, Davis, Dobbin, Kaufman \& Klass (n.d.) describe as there are two ideological poles, representing the prevailing tendencies within the feminist movement; one directs toward personal liberation and growth as part of new lifestyles within a women's culture. And, second emphasizes on structural analysis with recognition of existing diversity in society and its economic base, focusing on production relation. They suggest that socialist feminists share both the personal and the structural analysis.

Socialist feminist recognize the diversity among women focus on addressing them differently, similarly it is not possible to achieve substantive equality for all. They see the ideology is one of the important factors to develop strategy and tactics and setting the priorities to give an overall focus of work. Key ideological understanding of socialist feminist is that all issues are political, are based on power relation. That's why; all the actions must have political implications.

Based on the way and issues of the movement, foundation of the 


\section{6| Binda Pandey}

Nepali feminist movement can be counted onward Youmaya's rebellion action in 1917, which is approaching to almost a century. It has passed through having experiences of different mode of the feminism. And, the contribution of the different mode of the feminist movement should be valued and taking into account the achievement in the course of history. Nepali feminist movement has arrived to realize that diversity in nature based on geography as well as human values is the basis of the prosperity and unity among diversity is the strength of Nepali society.

\section{Conclusion}

Women have been treated differently all over the world. It is very widely based on political, economic and social status of the different society and the women's status, which was achieved through feminist movement. Women status in developed world, functioning as welfare state, is far better than third world (UNDP, 2013). But, their experience and knowledge are still different from male. One or another way, those women also have less influence in public decision-making process to. Even though the women are physically participating in different power mechanisms, they certainly experiencing and acquiring knowledge differently. But, their different knowledge and experience from their own standpoint are hardly respected and taken into decision-making process.

Feminist research acknowledges that most women face some form of oppression and exploitation (Kralik et al., n.d.). Feminist standpoint theory takes them into account those oppression, exploitation and differences. Seeing the things with feminist standpoint may narrow down the negativity and mainstream the knowledge and experiences of women, which has been historically ignored, oppressed, peripheral, discriminated, left-out and subordinated.

Feminist standpoint has identified defect in the traditional ethical way of viewing women as a whole, which give the shortsighted opinion. It gives emphasis on developing alternative approaches to change the power relation, system, structure, values, norms, attitude and role. In fact, it is the way of shifting social paradigm toward achieving equal human dignity and status among different sexes. For the cause, caring/private as well as status/public matter could be 
taken into account with equal importance.

Different feminist approaches see the way of changing women's lives differently. Criticality of Marxist philosophy has close link with feminist standpoint, which can be useful to mainstream the knowledge and experiences produce in the process of working in productive area. But, the caring role cannot be ignored, mostly performed by women, which is not in focus of Marxist way of analysis.

Working as social change agent, keeping eyes and pouring energy to transform society, with respecting co-existence and cooperation in all aspect of life, dignity and role in private and public sectors is important and to take into account the women's knowledge and experiences as biggest group of marginalized, subordinated and oppressed population, feminist standpoint theory should apply in the process of researching the fact. In this regard, the idea and argument of Ardhanareswor should be mainstreamed with the socialist feminist standpoint, respecting diverse experiences and perspectives created by existing culture, nature and production as well as power relation in the respective society.

\section{Reference}

Basow, S. A., \& Rubenfeld, K. (2003). "Troubles talk”: Effects of gender and gender typing.

Benton, T. \& Craib, I. (2010). Philosophy of social science. New York: Palgrave Macmillan.

Booth, H., Creamer, D., Davis, S., Dobbin, D., Kaufman, R. \& Klass, T. (n.d). History is a weapon, socialist feminism: A strategy for the women's movement. Hyde Park chapter, Chicago women's movement Retrieved from http://www. historyisaweapon.com/defcon1/chisocfem.html

Bowell, T.(2011). Feminist standpoint theory. Internet encyclopaedia of philosophy, Retrieved from http://www.iep.utm.edu/femstan

Brooks, A. (n.d.). Feminist standpoint epistemology: Building knowledge and empowerment through women's lived experience. Retrieved from http://www.sagepub.com/sites/ 


\section{8| Binda Pandey}

default/files/upm-binaries/12936_Chapter3.pdf

Crawford, N. (n.d.). What do feminists mean by standpoint? How has this notion contributed to the development of a feminist epistemology?

DeVore, S. \& Martin, B. N. (2008). Ethical decision-making: Practices of female and male superintendents. Advancing women in leadership archives, Retrieved from http:// awljournal.org/awl_wordpress/ethical-decision-makingpractices-of-female-and-male-superintendents

Feminist ethics (2009). Retrieved from Stanford encyclopedia of philosophy:http://plato.stanford.edu/entries/feminismethics

Gilligan, C. (n.d.). In a Different voice: Psychological theory and women's development. Cambridge: Harvard University Press, pp.24-39. Retrieved from http://courseweb.stthomas. edu/sjlaumakis/Reading\%204-GILLIGAN.pdf

Gray, J. (1992). Men are from Mars, Women are from Venus: a Practical Guide for

Gur, R. (n.d.). The hardwired difference between male and female brains could explain why men are 'better at map reading'. Retrieved from http://www.independent.co.uk/ life-style/the-hardwired-difference-between-male-andfemale-brains-could-explain-why-men-are-better-at-mapreading-8978248.html

Hekman, S.C. (1997). Truth and method: Feminist standpoint theory revisited signs. University of Chicago, 22(2), pp.341-365.

Inter-Parliamentary Union (IPU), (2015). Geneva: Author. Retrieved from http://www.ipu.org/wmn-e/world.htm.

Kralik, D. \& Loon, A. M. (n.d). Feminist research: Approaches to research, pp. 35-42. Retrieved from http://www.elsevierhealth.com/media/us/ samplechapters/9780443102776/9780443102776.pdf.

Krolokke, C. (2000). Three waves of feminism- from suffragettes to Girls. Gender communication theories and analysis, University of Southern Denmark

Lakoff, R. T. (1975). Language and woman's place. New York: Harper \& Row.

Lieberman, S. (n.d.). Difference in male and female communication styles. Retrieved from http://www.simmalieberman.com/ articles/maleandfemale.html 
Littlejohn, S. W. \& Foss, K. A. (n.d.). Feminist standpoint theory. Encyclopedia of communication theory, Vol.1, p.396, Retrieved from https://books.google.com.np/books?id=2 veMwywplPUC\&pg=PA396\&dq=Standpoint + arises + rec ognizes+and+challenges + cultural+values + and + power $\&$ $\mathrm{hl}=\mathrm{en} \& \mathrm{sa}=\mathrm{X} \& \mathrm{ved}=0 \mathrm{ahUKEwj}-\mathrm{mruXxo3LAhWFxI4KH-}$ X7RDekQ6AEIGzAA\# $\mathrm{v}=$ onepage\&q=Standpoint $\% 20$ arises $\% 20$ recognizes $\% 20$ and $\% 20$ challenges $\% 20$ cultural $\% 20$ values $\% 20$ and $\% 20$ power $\& \mathrm{f}=$ false

Merchant, K. (2012). How men and women differ: Gender difference in communication styles, influence tactics and leadership style. CMC senior theses, paper 513. Retrieved from scholarship.claremont.edu/cmc theses/513, 2016

Mitchell, J. \& Mishra, S. (2000). Psychoanalysis and feminism: $A$ radical reassessment of Freudian psychoanalysis. New York: Basic Books.

Nisbett, R., Peng, K., Choi, I. \& Norenzayan, A. (2001). Culture and systems of thought: Holistic analytic cognition. Psychological review, 108(2), pp. 291-310.

Preece, J. (n.d). Gender and learning feminist perspective. The routledge international handbook of learning, p.69. Retrieved from https://books.google.com.np/

Solberg, A. G. (2013). Male and female leadership styles. Retrieved from http://www.bps.org.uk/news/male-and-femaleleadership-styles

Tannen, D. (1990). You Just Don't Understand: Women and Men in Conversation. Ballantine Books, New York

United Nations (1995). Beijing platform for action. Retrieved from http://www.unwomen.org/ /media/headquarters/ attachments/sections/csw/pfa_e final_web.pdf

Winkler, C. (2004). Feminist Sociological Theory, Historical Developments and Theoretical approaches in Sociology, vol. II, Department of Sociology, The University of Montana, USA

Pandey, Binda holds Master Degrees in Gender and Development Studies from AIT, Thailand and in Botany Tribhuvan University, Nepal. She has published books on Women Participation in Nepalese Labour Movement and Student Movement in Nepal. Similarly, she is co-writer of "training materials" on gender and workers' human right. 


\section{0| Binda Pandey}

She occasionally writes article for broadsheet newspaper as well. She is an activist for gender equality and working people's right. She has served as a founder member of National Women Commission (NWC) from 2002 to 2004 and hold the position as chair of the fundamental right and directive principle committee of constituent assembly from 2008 to 2012. Currently, she is representing workers from Asia pacific region in ILO Governing Body since 2011 and the member of politburo of CPN (UML).

Email: binda.pandey@gmail.com 